\title{
Main effects of sleep disorders related to shift work-opportunities for preventive programs
}

\author{
Stojan Bajraktarov • Antoni Novotni • Nensi Manusheva • Dance G. Nikovska • \\ Elizabet Miceva-Velickovska • Natasha Zdraveska • Valentina C. Samardjiska • \\ Kneginja S. Richter
}

Received: 22 May 2011 / Accepted: 25 September 2011 / Published online: 21 October 2011

(C) European Association for Predictive, Preventive and Personalised Medicine 2011

\begin{abstract}
The sleep-related problems of shift workers usually occur as transient phenomena related to the timing of work. Sleep disorders, related to sleep deprivation, have
\end{abstract}

S. Bajraktarov $(\bowtie) \cdot$ A. Novotni $\cdot$ N. Manusheva

E. Miceva-Velickovska $\cdot$ V. C. Samardjiska

University Clinic of Psychiatry, University Cyril and Methodius,

Skopje, Macedonia

e-mail: stojan.bajraktarov@gmail.com

S. Bajraktarov $\cdot$ A. Novotni $\cdot$ N. Manusheva $\cdot$

E. Miceva-Velickovska • V. C. Samardjiska

University Clinic of Psychiatry,

Belgradska b.b.,

1000 Skopje, Republic of Macedonia

D. G. Nikovska

Ministry of Health, Republic of Macedonia,

Skopje, Macedonia

\section{N. Zdraveska}

Private organization,

Skopje, Macedonia

\section{K. S. Richter}

Clinic for Psychiatry and Psychotherapy,

Prof. Ernst-Nathan Str.1,

90419 Nuernberg, Germany

\section{G. Nikovska}

Ministry of Health, Republic of Macedonia, Ministry of Health, 50 Divizija,

1000 Skopje, Republic of Macedonia

\section{N. Zdraveska}

University Clinic of Psychiatry,

ONE, 1000,

Skopje, Republic of Macedonia

K. S. Richter

Clinic for Psychiatry and Psychotherapy,

Nuernberg, Germany a major impact on the quality of life and health status of healthcare workers. Reduced quantity and quality of sleep negatively affects the activities of shift workers, particularly in terms of their social functioning, quality of life and health. However, it seems that health authorities and the medical staff are negligent when it comes to the negative effects on health caused by work in night shifts. Recently published studies in this field suggest that appropriate public health preventive programs dealing with sleep disorders successfully contribute towards the quality of life of workers.

Keywords Health promotion - Health prevention - Shift work $\cdot$ Shift work sleep disorder $\cdot$ Health workers

\section{Introduction}

The sleep-related problems of shift work usually occur as transient phenomena related to the timing of work [1]. Complaints are usually related to the inability to sustain long-quality sleep after a night shift. These conditions can be accompanied by intense feelings of fatigue and drowsiness or lack of sleep, as well as reduced capacity for mental functioning due to lack of vigor and willingness to adequately respond to the tasks. Reduced levels of alertness or willingness to respond to everyday tasks are resulting in reduced capacity for performance of everyday activities not just during the night shifts, which in turn reflect on various aspects of personal safety. Increased level of irritability is also notable, which probably stems from the conflict caused by the need for sleep and the need for social activities [2].

Work in the health sector is often associated with night shifts. However, it seems that health authorities and the 
medical staff are negligent when it comes to the negative effects on health caused by work in night shifts. Several studies clearly show that this can pose a significant public health problem. Studies shows that night shift health workers experience increased fatigue, irritability, decreased work efficiency and reduced mental agility [3]. Increased risk of accidents at work is more commonly found in healthcare settings where employees work night shifts [4]. Night shift work in the healthcare sector is also associated with poorer health, increased frequency of absence from work and lower levels of job satisfaction [5].

Night shift work and high stress at the workplace are important characteristics of health sector work, primarily because of possible adverse effects on health of health workers and their safety. Night shift work is associated with an increased number of sleep disorders, multiple mental health problems, frequency of cardiovascular and gastrointestinal diseases, and dissatisfaction with the workplace, reduced work activities, increased work absences $[6,7]$.

Researchers have come to the conclusion that the reason for the negative effects of night shift work in healthcare comes from the bio-psycho-social challenges of the general schedule and length of time. Influence of night shift work is involved primarily in the disruption of natural day-night rhythm of individuals, which primarily result in effects on mental health, with signs of fatigue and break the rhythm of social/family plan. The role of cognitive processes and assessments have become increasingly important role in scientific explanation of the role of night shifts [8].

\section{Public health aspects}

The incidence of shift work sleep disorder stands in direct correlation with the prevalence of night work among the population. It is estimated that in the developed industrial countries about $20 \%$ of workers work night shifts [9]. On average, it is estimated that between $5 \%$ and $8 \%$ of the population have irregular working hours, including night shifts. Hence, the assumption is that between $2 \%$ and $5 \%$ of the population experiences problems associated with lack of sleep due to night-time shifts [10].

Sleep disorders, including sleep deprivation, have major impact on patients' quality of life. Patients with sleep disorders spend twice as many days in bed on annual level due to illness than patients without a sleep disorder. Also, the aforementioned group has 3-4 more days of absence from work due to illness, associated with $25 \%$ higher healthcare costs [11].

Scientific research in primary healthcare has shown that sleep disorders are associated and lead to problems in functioning, reduced productivity, and increased utilization of health services. The results of a survey by Gallup Institute, carried out for the U.S. National Association of Sleep show that as many as $58 \%$ respondents experience some kind of sleep problems during the year, whereas $24 \%$ respondents have insomnia. Some experts have found that the prevalence of sleep disorders among patients in the primary care sector is $69 \%(50 \%$ and $19 \%$ occasional chronic disorders of sleep) [12]. Many studies indicate that chronic sleep problems are often associated with depression, problems with work performance, chronic pain, chronic health conditions, and increased risk of accidents [13]. Sleep deprived individuals are more prone to sickness, have more trouble concentrating at work and are likely to undergo more medical examinations [14].

\section{Individual tolerance to shift work}

Number of studies carried out by eminent authors confirm the high inter-individual variability of tolerance towards shift work [15-17]. For example, age can affect the adaptability to the shift work. On the other hand, younger people may find it difficult to adapt to night work because they are sensitive to acute sleep loss, or because night shift work impedes their ability for integration in social events.

In line with these findings, study results indicate that good physical fitness and proper sleep hygiene can be beneficial in terms of tolerance towards the challenges associated with night shift work. Namely, it can increase efficiency, reduce fatigue, and boost the ability for rapid recovery of person's social and employment capacities [18].

"Commitment" to night shift work, the ability of workers to adapt their daily habits and activities to the night shifts seems to be an important determinant of this tolerance [19]. However, previous studies did not determine the extent to which individual characteristics influence long-term tolerance to night shift work and whether they can be used as possible predictors of such tolerance.

On the other hand, night time work may be well received (or even preferred) by people who are more able or willing to use daytime hours for other personal needs and preferences, such as additional education, other work commitments or various social activities [20,21].

Sleep deprivation outcomes

Assessment of the effects of shift work among health care workers in Italy shows that shift work significantly affects the quality of sleep, which in turn reflects on the health and overall functioning of this population group 
[22]. It is confirmed that problems associated with sleep deprivation are most evident in night shift workers [22]. Individuals working night shifts are at increased risk for significant behavioral and health-related morbidity associated with symptoms related to their altered day-night rhythm, in relation to individuals' working day shifts only [23]. Results of other study suggests that nurses need to allow extra time for sleep between shifts, in order to reduce the negative impact of night shift work on sleep, thus enhancing quality of sleep and consequently being able to offer better patient service [24] About one-third of night shift workers took afternoon naps; and study also found that night shifts were also characterized by increased subjective and objective sleepiness) [25-27]. Increased sleepiness, as emphasized in several studies, is associated with an increased risk of accidents [28].

According to the study which processed data about 895 nurses working full time, almost $67 \%$ of the nurses reported at least one episode of falling asleep behind the wheel, which happened on average after every fourth night shift [29]. According to other study, medicine residents working five or more extended night shifts for over a month are at significantly higher risk of falling asleep while driving or being stuck in traffic compared to the group that had no night shifts. The chances of an accident after extended night shift were more than twice as likely to occur, compared to normal shift [30].

\section{Exposure to light}

One of the reasons for sleepiness among night shift workers is the fact that the person is at work during the time of day when the organism is at its lowest level of functional efficiency, as expressed by many physiological and psychological variables [31]. Exposure to light plays a major role in changing the rhythm. Namely, exposure to light in the early hours, during the lowest level of functional efficiency will delay the need for sleep, whereas afterwards, daybreak will lead to faster onset of the need for sleep. Certain studies show that hospital personnel, especially nurses working night shifts, have difficulty staying awake at work, and are more prone to sleepiness during the day, with all the repercussions described above [32].

Influence of shift work on workers' mental health

According to research studies, night shift workers are dissatisfied with their work, whereas those exhibiting distinct signs of depression have a significantly higher Epworth score compared to those with opposite characteristics. These results suggest that the potential predictive features of daytime sleepiness are job dissatisfaction and depression symptoms among shift workers. According to the International Classification of Sleep Disorders, the characteristics of sleep disorders (shift work type) are as follows: difficulty concentrating, headaches and lack of energy. EIRO research shows that the majority of consequences stemming from sleep problems among night shift personnel include increased number of accidents, increased number of errors at the work place, increased absence from work due to sick leave, increased irritability, mood-related problems [33, 34].

Disruption of circadian rhythms affects the psychological aspects of employee's personality, and several trials show increased anxiety and depression symptoms. Undoubtedly, organization of preventive educational programs in this field should be the first step in tackling this problem [35]. The perception and decision-making ability can also be affected. All these factors can contribute to accidents and injuries. Some evidence suggests that night shift workers have a reduced ability to respond to emergencies effectively.

\section{Influence of shift work on workers' somatic health}

According to increasingly recognized research, employees whose work schedule includes night shifts manifest the following common health symptoms and effects:

Gastrointestinal problems, particularly peptic ulcersthese conditions are more common among night shift employees [36]. According to several studies, cardiovascular diseases and heart attacks occur more frequently in certain occupational groups working night-time shifts [37]. Sleep deprivation can also modify certain medical conditions as well as the effectiveness of drugs. For example, in a worker suffering from epilepsy, sleep deprivation can aggravate the condition and exacerbate the symptoms [38].

It is also found that diabetes and metabolic disorders are more common among employees whose work includes night shifts [39]. In a study involving 469 nurses over a 5 year span, it is found a higher increase in BMI among night shift nurses compared to day shift nurses [40]. Results of other study found a higher incidence of diabetes mellitus among night shift workers [41]. Several recent studies show that sleep deprivation can affect blood sugar levels [42].

Impact on social aspects of health

According to the World Health Organization, social and personal problems are more prevalent among night shift healthcare workers, compared to those working day shifts only. Irregular shifts tend to cause more social and subjective problems and dissatisfaction at work. 
According to the same study, night shift health workers use more sedatives than their colleagues who only work day shifts. The study emphasizes the need for introducing strategies to combat the harmful effects of nightshift work among health workers, in order to improve their health [43]. Some authors note that the adjustment of night shift work to the social aspects of person's life can significantly facilitate the adaptation and tolerance to night shifts $[44,45]$.

It is important to mention that according to research done in developing countries (ILO survey), less favorable living conditions as well as lack of social protection and support, often associated with inadequate working conditions and long working hours may emphasize the negative impacts of night work on the health of workers [46].

\section{Work ability}

Sleepiness, sleep disturbances, chronic fatigue and oscillatory fluctuations of alertness and vigilance can be important contributing factors to 'human error', and consequent work accidents and injuries. This is documented in many groups of shift workers, not only those on night shifts but also those on day shifts, as well as in relation to duty hours, successive shifts and prolonged duty periods [47].

\section{Recommendations for prevention programs}

Taking into consideration that shift work causes a large number of somatic and psychiatric diseases which bear considerable negative consequences for the health status and the quality of life, it seems to be important to initiate health promotion strategies for shift workers. The results of recent studies indicate that well-scheduled und targeted health programs can change the lifestyle of shift working employees and have an impact on the risk factors involved [48]. Several activities are recommended in order to improve the health status of healthcare personnel, whose work involves night shifts. Activities to promote health and prevention should aim to improve the following:

- Quality of sleep

- Social interaction

- Health status

- Educational activities

Activities for improvement of quality of sleep

ILO Convention No. 171 on night work (International Labour Office, 1990), as well as the European Directive No. 104/1993 concerning 'certain aspects of the organisa- tion of working time' (European Council Directive, 1993), states that workers shall be entitled '... to undergo a free health assessment before their assignment to night work and thereafter at regular intervals, and in case they experience health problems because of it' [49]. Guidelines for medical surveillance have been published by, among others, Rutenfranz [50], and Costa and Pokorski [51]. Adequate and regular healthcare should also be ensured, which will identify various sleep disorders and treat them accordingly. The work environment should be adjusted in order to promote wakefulness and alertness, such as adequate illumination or music. Another issue of great importance is the participation and involvement of workers themselves in the creation of the shift work design [52].

Activities for improvement of social interaction

Different kinds of social activities inside the organization should be supported, including organization of regular social events by the management. The organization of sport events is important both from a social aspect, as well as the aspect of person's physical and mental health. If possible, childcare service should be arranged [53].

\section{Activities for improvement of health status}

Appropriate healthcare should be arranged, including screening for mental disorders/and or symptoms. Various workshops and informative sessions for recognition and management of symptoms associated with stress need to be organized. Workshops and sessions focused on relaxation techniques should also be provided, such as yoga, as well as workshops on teamwork and conflict management. Educational activities regarding appropriate nutrition for night shift workers should also be organized. Regular periodical medical health checkups are responsibility of the employer, but also of the health workers. Support or organization of different physical and recreational activities can significantly improve employees' health status [50, 53].

\section{Educational activities}

The health management sector should organize educational programs for health workers who work night shifts, primarily for appropriate sleep hygiene, and for appropriate adaptation and organization of night shift work activities. Different educational workshops should be organized on regular basis, aimed for identification and dealing with the stress related symptomatology, for teamwork, and conflict management, as well as adequate nutrition education [54]. Educational programs should be organized for both employers and for workers and all stakeholders. Education to provide oversight and supervi- 
sion proved as an effective method. Regular education is needed to effectively implement emergency response procedures $[55,56]$. The educational programs should focus on the design work night shifts. Care should be taken to the workers isolation aspect, and should provide guidelines for regular communication with employees working alone. It is necessary to include all workers in educational activities on violence [57].

\section{Conclusions}

Considering the facts stated above, several main conclusions can be derived:

- The characteristics of sleep in the group of health workers with shift work are indicative of presence of sleep disorders.

- Night shift work strongly affects quality of sleep, hence sleep disorders are common in this group of workers.

- Reduced quality of sleep negatively affects professional activities of night shift health workers, their social interactions and overall quality of life.

- The accumulated sleep deficit in this group of health workers can lead to serious disruptions in their daily life routine, including excessive sleepiness during the day, poor quality of sleep and chronic fatigue.

- Health prevention and promotion programs are most important for overcoming the consequences of shift work type sleep disorders.

\section{References}

1. Akerstedt T. Working hours, sleepiness and the underlying mechanisms. J Sleep Res. 1995;4(S2):15-22.

2. Knauth P, Rutenfranz J. Duration of sleep related to the type of shift work. In: Reinberg A, Vieux N, Andlauer P, editors. Night and Shift Work: Biological and Social Aspects. Oxford: Pergamon Press; 1981. pp. 161-8.

3. Huges R, Stone P. The perils of shift work: evening shift, night shift, and rotating shifts: are they for you? Am J Nurs. 2004;104(9):60-3.

4. Zhao I, Bogossian F, Turner C. Shift work and work related injuries among health care workers: A systematic review. Aust J Adv Nurs. 2010; 27(3):62-74.

5. Burch JB, Tom J, Zhai Y, Criswell L, Leo E, Ogoussan K. Shiftwork adaptation among health care workers. Occup Med (Lond). 2009;59(3):159-66.

6. Muecke S. Effects of rotating night shifts: literature review. J Adv Nurs. 2005;50:433-9.

7. Poissonnet CM, Veron M. Health effects of work schedules in healthcare professions. J Clin Nurs. 2000;9:13-23.

8. Haider M, Kundi M, Koller M. Methodological issues and problems in shift work research. In: Johnson L, Tepas D, Colquhoun P, Colligan M, editors. Biological rhythms, sleep and shift work. Jamaica: Spectrum; 1981. pp. 145-63.

9. Presser H. Towards a 24-hours economy. Science. 1999;284:1778-9.
10. Akertsedt T. Shift work and disturbed sleep/wakefulness. Occup Med (Lond). 2003;53(2):89-94.

11. Simon GE, VonKorff M. Prevalence, burden, and treatment of insomnia inprimary care. Am J Psychiatry. 1997;154(10):1417-23.

12. Shochat T, Umphress J, Israel AG, Ancoli-Israel S. Insomnia in primary care patients. Sleep. 1999;22 Suppl 2:S359-65.

13. Benca RM. Consequences of insomnia and its therapies. J Clin Psychiatry. 2001;62 Suppl 10:33-8.

14. Leger D, Guilleminault C, Bader G, Levey E, Palliard M. Medical and socio-professional impact of insomnia. Sleep. 2002;25:625-9.

15. Costa G. Shift work and occupational medicine: an overview. Occup Med (Lond). 2003;53:83-8.

16. Härmä M. Individual differences in tolerance to shiftwork: a review. Ergonomics. 1993;36:101-9.

17. Nachreiner F. Individual and social determinants of shiftwork tolerance. Scand J Work Environ Health. 1998;24 Suppl 3:35-42.

18. Härmä M. Ageing, physical fitness and shiftwork tolerance. Appl Ergon. 1996;27:25-9.

19. Rosa R. Editorial: factors for promoting adjustment to night and shift work. Work Stress. 1990;4:201-2.

20. Loudoun R, Bohle P. Work/non-work conflict and health in shift work: relationships with family status and socialsupport. Int J Occup Environ Health. 1997;3:S71-7.

21. Walker J. Social problems of shift work. In: Folkard S, Monk T, editors. Hours of work: temporal factors in work scheduling. Chichester: Wiley; 1985. pp. 221-5.

22. Conway PM, Campanini P, Sartori S, Dotti R, Costa G. Main and interactive effects of shiftwork, age and work stress on health in an Italian sample of healthcare workers. Appl Ergon. 2008; 39:630-9.

23. Drake CL, Roehrs T, Richardson G, Walsh JK, Roth T. Shift work sleep disorder: prevalence and consequences beyond that of symptomatic day workers. Sleep. 2004;27(8):1453-62.

24. Ohida T, Kamal A, Sone T, Ishii T, Uchiyama M, Moniwa M et al. Night-shift work related problems in young female nurses in Japan. J Occup Health. 2001;43:150-6.

25. Åkerstedt T, Kecklund G, Knutsson A. Spectral analysis of sleep electroencephalography in rotating three-shift work. Scand J Work Environ Health. 1991;17:330-6.

26. Åkerstedt T, Torsvall L. Napping in shift work. Sleep. 1985;8:105-9.

27. Kecklund G, Åkerstedt T. Sleepiness in long distance truck driving: an ambulatory EEG study of night driving. Ergonomics. 1993;36:1007-17.

28. Folkard S, Tucker P. Shift work, safety and productivity. Occup Med (Lond). 2003;53:95-101.

29. Scott LD, Hwang WT, Rogers AE, Nysse T, Dean GE, Dinges DF. The relationship between nurse work schedules, sleep duration, and drowsy driving. Sleep. 2007;30(12):1801-7.

30. Barger LK, Cade BE, Ayas NT, Cronin JW, Rosner B, Speizer FE, Czeisler CA. Extended work shifts and the risk of motor vehicle crashes among interns. N Engl J Med. 2005; 352:125-34.

31. Fröberg JE, Karlsson CG, Levi L, Lidberg L. Psychobiological circadian rhythms during a 72-hour vigil. Försvarsmedicin. 1975; II:192-201.

32. Lee-Chiong TL. [ed]. Sleep: a comprehensive handbook. Hoboken, NJ, Wiley-Liss; 2006.

33. The European Industrial Relations Observatory (EIRO). Working time developments - 2006 .

34. Manuseva N, Bajraktarov S, Stefanovski B, Novotni A, Rihter Sokolovska K, Dimovski D. Sleep disorders in psychiatry. MPA Congress Journal, Ohrid 2009;0-33.

35. Colligan MJ, Rosa RR. Shiftwork effects on social and family life. Occup Med. 1990;5:315-22.

36. Scott AJ, LaDou J. Health and safety in shift workers. In: Zenz C, Dickerson OB, Horvath EP, editors. Occupational Medicine. St Louis: Mosby; 1994. pp. 960-86. 
37. Bøggild H, Knutsson A. Shift work, risk factors and cardiovascular disease. Scand J Work Environ Health. 1999;25:8599.

38. Pratt KL, Mattson RH, Weikers NJ, Williams R. EEG activation of epileptics following sleep deprivation: a prospective study of 114 cases. Electroencephalogr Clin Neurophysiol. 1968;24:11-5.

39. Theorell T, Akerstedt T. Day and night work: changes in cholesterol, uric acid, glucose and potassium in serum and in circadian patterns of urinary catecholamine excretion. Acta Med Scand. 1976;200:47-53.

40. Niedhammer I, Lert F, Marne MJ. Prevalence of overwight and weight gain in relation to night work in a nurses' cohort. Int J Obes Relat Metab Disord. 1996;20:625-33.

41. Koller M, Kundi M, Cervinka R. Field studies of shift work at an Austrian oil refinery. I: Health and psychosocial wellbeing of workers who drop out of shift work. Ergonomics. 1978;21:83547.

42. Spiegel K, Leproult R, VanCauter E. Impact of sleep debt on metabolic and endocrine function. Lancet. 1999;354:1435-9.

43. Choobineh A, Rajaeefard A, Neghab M. Problems related to shift work for health care workers at Shiraz University of Medical Sciences East Mediterr Health J. 2006; 12:340-6.

44. Wedderburn A, editor. Bulletin of European Studies on Time No. 4. Compensation for Shiftwork. Dublin: European Foundation for the Improvement of Living and Working Conditions; 1992.

45. Pisarski A, Bohle P, Callan VJ. Effects of coping strategies, social support and work-non work conflict on shift workers health. Scand J Work Environ Health. 1998;24:141-5.
46. International Labour Office. Night Work. Report V/1. Geneva: ILO; 1988.

47. Monk TH, Folkard S, Wedderburn AI. Maintaining safety and high performance on shift work. Appl Ergon. 1996;27:17-23.

48. Richter KD, Acker J, Scholz F, Niklewski G. Health promotion and work: prevention of shift work disorders in companies. EPMA J. 2010;1:611-8.

49. Kogi K. International regulations on the organization of shift work. Scand J Work Environ Health. 1998;24 Suppl 3:7-12.

50. Rutenfranz J. Occupational health measures for night and shift workers. J Human Ergol (Tokyo). 1982;11(Suppl):67-86.

51. Costa G, Pokorski J. Effects on health and medicalsurveillance of shift workers. In: Marek T, Oginska H, Pokorski J, Costa G, Folkard S, editors. Shift work 2000 implications for science, practice and business. Krakow: Institute of Management, Jagiellonian University; 2000. p. 71-97.

52. Knauth P, Hornberger S. Preventive and compensatory measures for shift workers. Occup Med (Lond). 2003;53:109-16.

53. Knutsson A. Health disorders of shift workers. Occup Med (Lond). 2003;53:103-8.

54. Costa G. Guidelines for the medical surveillance of shift workers. Scand J Work Environ Health. 1998;24 Suppl 3:151-5.

55. Knauth P. The design of shift systems. Ergonomics. 1993;36:15-28.

56. Totterdell P, Folkard S. The effects of changing from weekly rotating to a rapidly rotating shift schedule. In: Costa $G$, Cesana G, Kogi K, Wedderburn A, editors. Shiftwork: health, sleep and performance. Frankfurt: Peter Lang; 1990. pp. 646-50.

57. Knauth P. Innovative worktime arrangements. Scand J Work Environ Health. 1998;24 Suppl 3:13-7. 